\title{
On reification: a reinterpretation of designed and emergent practice - a reply
}

\author{
Paul Joyce* and Bernard Lisewski*** \\ *UMIST, ** University of Salford \\ email: b.lisewski@salford.ac.uk
}

We welcome the response of Chris Tompsett and Graham Alsop to our article (Lisewski and Joyce, 2003). Within its 'stricter analysis', it is thoughtful and incisive, presenting an interesting critique of our ideas. How'ever, we cannot help but think that the authors have missed the point. Indeed, if we wish to be mischievous we would argue that their response is an exemplar of some of the concerns we wanted to raise in our original article.

\section{The emergent learning technology profession}

The most notable thing about Tompsett's and Alsop's response is its marked unwillingness to enter into a critical and reflexive debate about the emergent learning technology profession and its search for 'academic legitimacy' within the HE professional milieu. At the outset, the authors acknowledge the problems of commodification and the growing influence of management discourses in the HE sector, yet they singularly fail to engage with these core issues. Instead they retreat into a narrow debate about the use and applicability of the 'communities of practice' paradigm.

To be fair, the learning technology community is a broad church. There is a wide array of disciplines and theoretical understanding of what constitutes good professional practice and how it should be evaluated. The authors' use of the term 'anecdotal' to characterize some of our research methodology does seem to indicate that they are more familiar and more comfortable with technology-related disciplines and their concomitant research strategies. Perhaps this is why they feel the need for 'stricter' forms of analysis and overarching theoretical frameworks. However, it appears to us, as stated in the original article, that this is problematic for a developing profession. The rush to adopt allencompassing analytic structures is often the antithesis of a self-critical understanding of dominant professional practices. Unfortunately, there are clearly no easy solutions that will 
somehow allow the researcher to understand the totality of emergent phenomena. The self-critical path for a profession is often hard, incomplete and sometimes contradictory but it does hold forth the prospect of deeper knowledge and a degree of intellectual detachment.

Couched in these terms the alternative 'application of a single framework from the design of the activity through to evaluation and analysis' does look tempting as it seemingly offers certainty, familiarity and direction. But there is a price to be paid. As the response authors demonstrate, there is a danger of debates within dominant analytical frameworks becoming too self-referential, more concerned with defining terms than observing messy practice and the nexus of power in which it operates - which, as their penultimate paragraph illustrates, has led them into a contradictory position. As they argue, single frameworks are critical but different frameworks produce different conclusions. So how do we decide which is best? Further to this question, what is the wider context that allows us to make these decisions?

\section{Seeing the big picture}

Clearly, in adopting highly reified theoretical structures there is the danger of missing the 'big picture'. The 'communities of practice' notion is interesting and does present a useful way of conceptualizing emergent practice. However, it has one major flaw, which Lave and Wenger (1991: 42) have acknowledged, in that the very notion of power relations that underlie the development of professional practice and legitimacy is noticeably underdeveloped from within their analysis:

In particular, unequal relations of power must be included more systematically in our analysis. Hegemony over resources for learning and alienation from full participation are inherent in the shaping of the legitimacy and peripherality of participation in its historical realizations.

In many ways this is the extra dimension our paper attempted to address. As we argued (ibid.: 62-3):

Professional practice cannot be viewed as separate from the concept of authority and the exercise of power ... the route to legitimacy within HE does not take place within a power vacuum, the terrain is already occupied and to some extent mapped by competing professional interests - political, managerial and educational. To become part of this professional milieu may mean that the pathway to validation and legitimization is not totally at the discretion of learning technologists themselves.

Commodification and managerial oversight are merely artefacts of underlying power relations. To widen the 'academic legitimacy' debate we adopted some of the familiar rhetoric of the 'communities of practice' literature but applied it more loosely than perhaps Tompsett and Alsop would have wished in order to make our points more forcefully. The learning technology profession is developing in an arena already well populated by powerful interest groups - be they managerial, academic or political. Any theoretical stance that seeks to understand how professional practice evolves has to acknowledge this context, that is, there is a need for us to be 'situating analysis within historical and contextual parameters' (Clegg, Hudson and Steele, 2003: 50). 
It was our intention to highlight these concerns in our original paper and to point out that this aspect of analysis is often missing from the debate about what constitutes 'academic legitimacy' within the learning technology profession as it seeks to establish its position within a mass HE system (Scott, 1995). The response to our paper by Tompsett and Alsop exemplifies this de-contextualization in practice, more concerned with the purity of the argument than engaging in any wider critical debate.

\section{References}

Clegg, S., Hudson, A. and Steele, J. (2003), 'The Emperor's New Clothes: globalisation and e-learning in higher education', British Journal of Sociology of Education, 24 (1), 39-53.

Lave, J. and Wenger, E. (1991), Situated Learning: Legitimate Peripheral Participation, Cambridge: Cambridge University Press.

Lisewski, B. and Joyce, P. (2003), 'Examining the five-stage e-moderating model: designed and emergent practice in the learning technology profession', ALT-J, 11 (1), 55-66.

Scott, P. (1995), The Meanings of Mass Higher Education, Buckingham: SRHE/OUP. 